\title{
Modeling the conscious correlates of recognition memory: Reflections on the remember-know paradigm
}

\author{
ELLIOT HIRSHMAN and SUSAN MASTER \\ University of North Carolina, Chapel Hill, North Carolina
}

\begin{abstract}
Understanding how memory processes contribute to the conscious experience of memory is central to contemporary cognitive psychology. Recently, many investigators (e.g., Gardiner, 1988) have examined the remember-know paradigm to understand the conscious correlates of recognition memory. A variety of studies have demonstrated that variables have different effects on remember and know responses, and these findings have been interpreted in the context of dual-process models of recognition memory. This paper presents a single-process model of the remember-know paradigm, emphasizing the dependence of remember and know judgments on a set of common underlying processes (e.g., criterion setting). We use this model to demonstrate how a single-process model can give rise to the functional dissociations presented in the remember-know literature. We close by detailing procedures for testing our model and describing how those tests may facilitate the development of dual-process models.
\end{abstract}

Understanding how memory processes contribute to the conscious experience of memory is central to contemporary cognitive psychology. Recently, Gardiner and his colleagues (see Gardiner \& Java, 1993, for a review) have examined a procedure designed to understand the conscious correlates of recognition memory. This procedure, aptly dubbed the remember-know paradigm, mimics the standard yes-no recognition test with one exception. When subjects judge an item to be from the prior study list, they are directed to make a judgment about the conscious experience motivating this response. Subjects write an $\mathrm{R}$ (for remember) next to a recognized item if they consciously recollect the item's occurrence in the study list. Alternatively, they write a $\mathrm{K}$ (for know) if they know the item occurred in the study list but cannot consciously recollect its occurrence.

The results of many experiments (Conway \& Dewhurst, 1995; Gardiner, 1988; Gardiner \& Java, 1990; Gardiner \& Parkin, 1990; Java, Kaminska, \& Gardiner, 1995; Jones \& Roediger, 1995; LeCompte, 1995; Parkin \& Walter, 1992; Rajaram, 1993; Yonelinas \& Jacoby, 1995) have demonstrated that variables have different effects on remember and know judgments. Some variables increase remember but not know judgments (Gardiner, 1988; Gardiner \& Java, 1990; Gardiner \& Parkin, 1990; Java et al., 1995; Jones \& Roediger, 1995). Other variables increase remember judgments but decrease know judgments (Con-

This research was supported by research grant SBR-9420248 from the National Science Foundation to E.H. The authors thank Martin Conway, John Gardiner, Tom Wallsten, and George Wolford for insightful comments on a prior version of this manuscript. Correspondence should be addressed to E. Hirshman, CB 3270, Department of Psychology, University of North Carolina at Chapel Hill, Chapel Hill, NC27599-3270 (e-mail: elliot@memlab.psych.unc.edu). way \& Dewhurst, 1995; Dewhurst \& Conway, 1994; Gardiner \& Java, 1990; Jones \& Roediger, 1995; Parkin \& Walter, 1992; Rajaram, 1993; Yonelinas \& Jacoby, 1995). Still others increase know judgments but not remember judgments (LeCompte, 1995; Rajaram, 1993).

One interpretation of these functional "dissociations" is that the remember and know judgments index two distinct bases of recognition memory (Jacoby \& Dallas, 1981; Mandler, 1980). In this view (Gardiner \& Java, 1993; Gardiner \& Parkin, 1990; Rajaram, 1993), remember judgments arise from an episodic memory system that is strongly influenced by conceptual processing. Know judgments, on the other hand, arise from a perceptual (or semantic) memory system that is strongly influenced by perceptual processing. Consistent with this interpretation, a levels-of-processing manipulation, hypothesized to affect conceptual representations, increases remember but not know responses (Gardiner, 1988; Rajaram, 1993). Similarly, pattern masking of test items, a manipulation hypothesized to affect perceptual processing, increases know but not remember responses (Rajaram, 1993). Buttressing this interpretation further are findings that a sureunsure judgment is not identical to the remember-know judgment (Gardiner \& Java, 1990; Parkin \& Walter, 1992; Rajaram, 1993) and that the remember and know judgments have different neural correlates (Smith, 1993).

There are, however, some problems with this general account (see Gardiner \& Java, 1993, Java et al., 1995, and Jones \& Roediger, 1995). First, Knowlton and Squire (1995) recently demonstrated that both remember and know responses are greater for control than amnesiac subjects. Fewer know responses for amnesiacs is problematic because know judgments are hypothesized to index perceptual memory systems, which are generally assumed to be intact in amnesiacs (Tulving \& Schacter, 1990). 
Second, Yonelinas and Jacoby (1995) demonstrated that increasing size congruency between study and test stimuli increased remember responses and decreased know responses. This is problematic because matching the perceptual attributes of stimuli between study and test should enhance perceptual processing, thus increasing know responses.

Third, Gardiner and Java (1990) demonstrated that nonwords produced more know responses than did words, while low- and high-frequency words produced an equal number of know responses. They explained the former finding by hypothesizing that less familiar items (i.e., nonwords) produce larger enhancements in perceptual processing, thus increasing know responses. This, however, makes the latter finding problematic because it implies that low-frequency words should also enjoy greater enhancements in perceptual processing, with accompanying increases in know responses.

Given these theoretical difficulties, we began to consider alternative conceptions of the remember-know paradigm. Our starting point in these explorations was the hypothesis that remember and know judgments might reflect decision, as well as memory, processes (see Hirshman, 1995, for a general discussion of the role of decision processes in recognition memory). To our surprise, we discovered that a simple model that relied on a single memory process and two criteria for the determination of remember, know, and new responses could reproduce the dissociations described above. The purpose of this paper is to describe this model, demonstrate how it produces the above dissociations, and consider some ways it can be used to further our understanding of the psychological processes operating in the remember-know paradigm.

\section{A Model of the Remember-Know Paradigm}

Our model is a variant of the classical signal detection model of recognition memory (Glanzer, Adams, Iverson, \& Kim, 1993; Green \& Swets, 1966) and is presented graphically in Figure 1. The figure represents the three basic assumptions of our model. First, items can be ordered on a familiarity or strength dimension. Familiarity is a continuous variable representing the evidence of an item's previous occurrence (Gillund \& Shiffrin, 1984). Thus, in contrast to the standard conception of the remember-know paradigm (Gardiner \& Java, 1993; Gardiner \& Parkin, 1990; Rajaram, 1993), the present approach assumes that a single underlying memory process contributes to both remember and know judgments.

Second, normal probability density distributions represent the overlapping familiarity distributions of old and new items. Figure 1 represents a case where there are two old distributions, corresponding to two study conditions, and a new distribution. Each distribution has an associated mean and variance and, for computational convenience, we will generally set the mean of the new distribution to 0 and its variance to 1 .

Third, subjects place two criteria on the familiarity axis to determine their judgments. A first criterion, denoted $\mathrm{C}$, is used to make old-new judgments. If the familiarity of an item is greater than $C$, subjects will call it "old." Otherwise, they call it "new." A second criterion, denoted $\mathrm{RC}$, is used to make remember-know judgments. Items whose familiarity is above RC will be given remember responses, and items whose familiarity is between the two criteria will be given know responses. Thus, the model posits a dependency between remember and know responses because, given a fixed $\mathrm{C}$, movement of

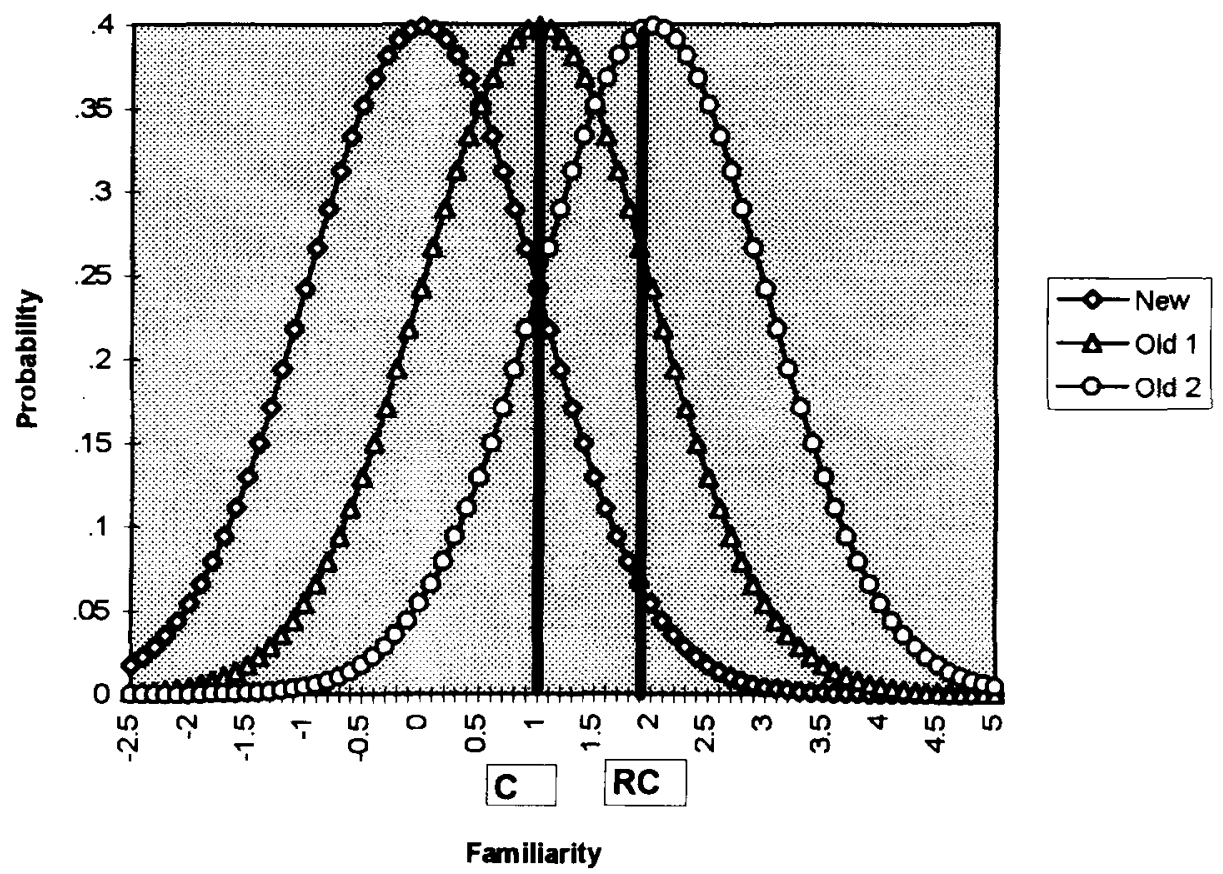

Figure 1. A model of the remember-know paradigm. 
RC produces tradeoffs between remember and know judgments. One can see this graphically in Figure 1 by noting that the proportion of remember responses in a study condition is represented by the area under the appropriate density function from $R C$ to infinity, whereas the proportion of know responses is represented by the area under this function from $\mathrm{C}$ to $\mathrm{RC}$.

The algebraic representation of the model uses the inverse of the cumulative normal to transform response proportions into the model's parameters. Specifically, for new distributions,

$$
\begin{aligned}
& Z_{\text {new }}(\mathrm{C})=\mathrm{C}=-1 * \Phi^{-1}\left(\mathrm{R}_{\text {new }}+\mathrm{K}_{\text {new }}\right), \\
& Z_{\text {new }}(\mathrm{RC})=\mathrm{RC}=-1 * \Phi^{-1}\left(\mathrm{R}_{\text {new }}\right),
\end{aligned}
$$

and for old distributions,

$$
Z_{\text {old }}(\mathrm{C})=\left(\mathrm{C}-\mu_{\text {old }}\right) / \sigma_{\text {old }}=-1 * \Phi^{-1}\left(\mathrm{R}_{\text {old }}+\mathrm{K}_{\text {old }}\right) \text {, }
$$

$Z_{\text {old }}(\mathrm{RC})=\left(\mathrm{RC}-\mu_{\text {old }}\right) / \sigma_{\text {old }}=-1 * \Phi^{-1}\left(\mathrm{R}_{\text {old }}\right)$,

where $\mathrm{C}$ and $\mathrm{RC}$ are the criteria as described previously, $R_{i}$ is the proportion of remember responses in Condition $\mathrm{i}, \mathrm{K}_{\mathrm{i}}$ is the proportion of know responses in Condition $\mathrm{i}, \mu_{\mathrm{i}}$ is the mean of the distribution representing Condition $\mathrm{i}$, and $\sigma_{i}$ is its standard deviation.

To understand the transformations represented in Equations 1-4, consider a simple experiment where there is only one old condition. In this case, there are four data points, $R_{\text {new }}, K_{\text {new }}, R_{\text {old }}$, and $K_{\text {old }}$, and four parameters, $\mathrm{C}, \mathrm{RC}, \mu_{\text {old }}$, and $\sigma_{\text {old }}$. Given the data, one can use Equations 1 and 2 to solve for $\mathrm{C}$ and RC. Then one can use the values of $\mathrm{C}$ and $\mathrm{RC}$, in conjunction with the data, to solve for $\mu_{\text {old }}$ and $\sigma_{\text {old }}$ in Equations 3 and 4. One would proceed similarly when there are two or more old conditions except that there would be a version of Equations 3 and 4 for each old condition. More complex situations involving multiple new distributions (see, e.g., Rajaram, 1993) can also be accommodated. In this case, one would use the false alarm rates $\left(R_{\text {new }}\right.$ and $\left.K_{\text {new }}\right)$ for a given new condition to solve for the criteria corresponding to that condition. Different old conditions would then use the appropriate criteria to solve for $\mu_{\text {old }}$ and $\sigma_{\text {old }}$ in Equations 3 and 4.

\section{Properties and Implications of the Model}

Although the model represented in Figure 1 may represent a relatively parsimonious conception of the remember-know paradigm, the results described previously seem to argue against its plausibility. For example, how can a model that posits a dependency between remember and know responses account for cases where variables affect remember but not know responses? Similarly, how can a model with a single underlying memory process account for cases where variables increase remember responses but decrease know responses?

In this section we answer these questions. The three panels of Figure 2 demonstrate graphically how one can produce a variety of functional dissociations in the cur- rent model. The top panel demonstrates a case where one condition (old 2) produces more remember responses than another condition (old 1), but the two conditions produce an equal number of know responses. The middle panel demonstrates a case where old 2 produces more remember responses than does old 1 , but old 1 produces more know responses than does old 2 . The bottom panel demonstrates a case where the two conditions produce an equal number of remember responses, but know responses are greater in old 1.

It is important to note that these patterns arise given extremely simple assumptions. In the top panel, old 2 is to the right of old 1 , and, given a single $\mathrm{RC}$, this increases remember responses. Know responses are approximately equal in the two conditions because the areas under the two curves between the two criteria are approximately equal. The latter condition, which allows a model that assumes a dependency between remember and know responses to produce a situation in which a variable influences only one response, is not an unlikely one. It will hold whenever the criteria and the peaks of two equalvariance, old distributions are all relatively close, as well as in a variety of special circumstances (e.g., two equalvariance, old distributions are widely separated, but the criteria are at the peaks of the distributions).

In the middle panel, the underlying distributions and $\mathrm{RC}$ are identical to those in the top panel. This produces the same pattern of remember responses. C's position, however, has decreased relative to that in the top panel. This produces a greater increase in the area under the old 1 distribution between $\mathrm{C}$ and $\mathrm{RC}$ because of the dependency of remember and know responses. This leads to more know responses in Condition 1 . Thus, a model that posits only a single memory process can produce a situation where a variable affects remember and know responses oppositely. This occurs when the dependency between the remember and know responses is coupled with particular criteria placement.

In the bottom panel, the old and new distributions are assumed to be identical for Conditions 1 and 2 , as is RC. This produces equal remember responses in the two conditions. Here, however, there are separate criteria $(\mathrm{Cl}$ and $\mathrm{C} 2$ ) determining old-new judgments for each condition, and the lower value of $\mathrm{Cl}$ produces more know responses in Condition 1. Note that subjects must be able to discriminate items in Conditions 1 and 2 at test to apply different criteria to them. Interestingly, both published studies (LeCompte, 1995; Rajaram, 1993) demonstrating differences in know but not remember responses satisfy this condition.

Before proceeding to a discussion of some possible uses of the present model, we wish to discuss one additional implication to help establish its plausibility. Specifically, the present model predicts that the effects of variables on know responses are likely to be less reliable than the effects of these same variables on remember responses. This is because shifts in criteria placement can produce changes in the relative number of know responses 


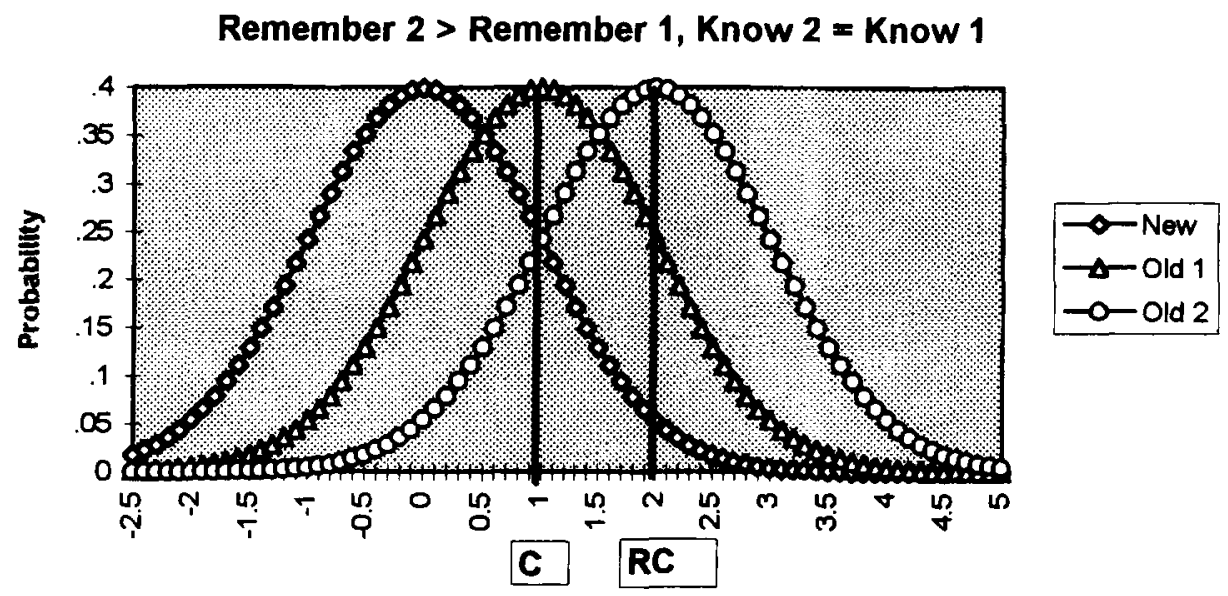

Familiarity

Remember $2>$ Remember 1, Know $1>$ Know 2
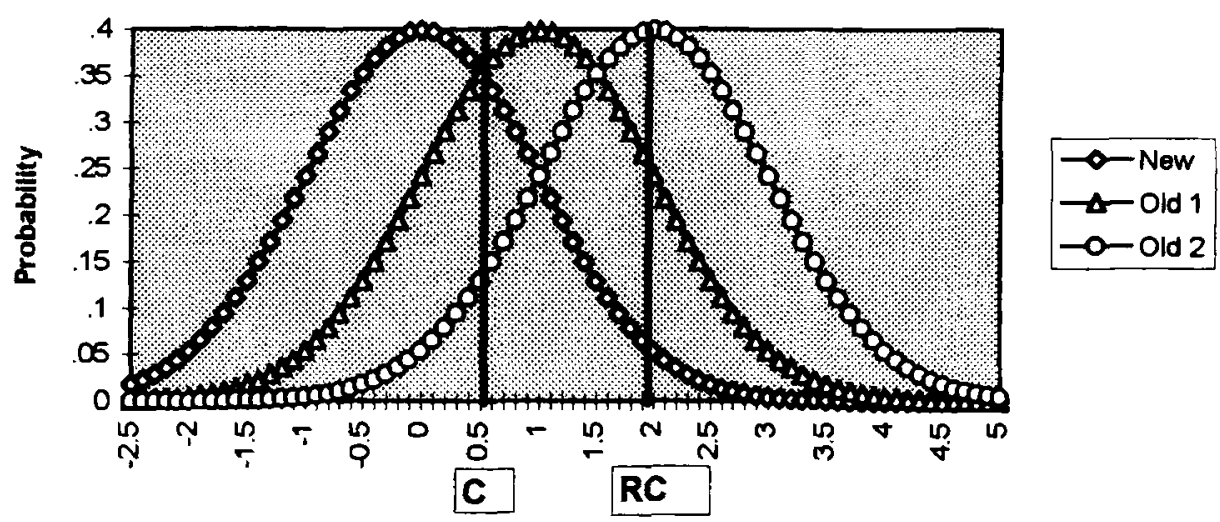

Famillartty

Remember 1 = Remember 2, Know $1>$ Know 2

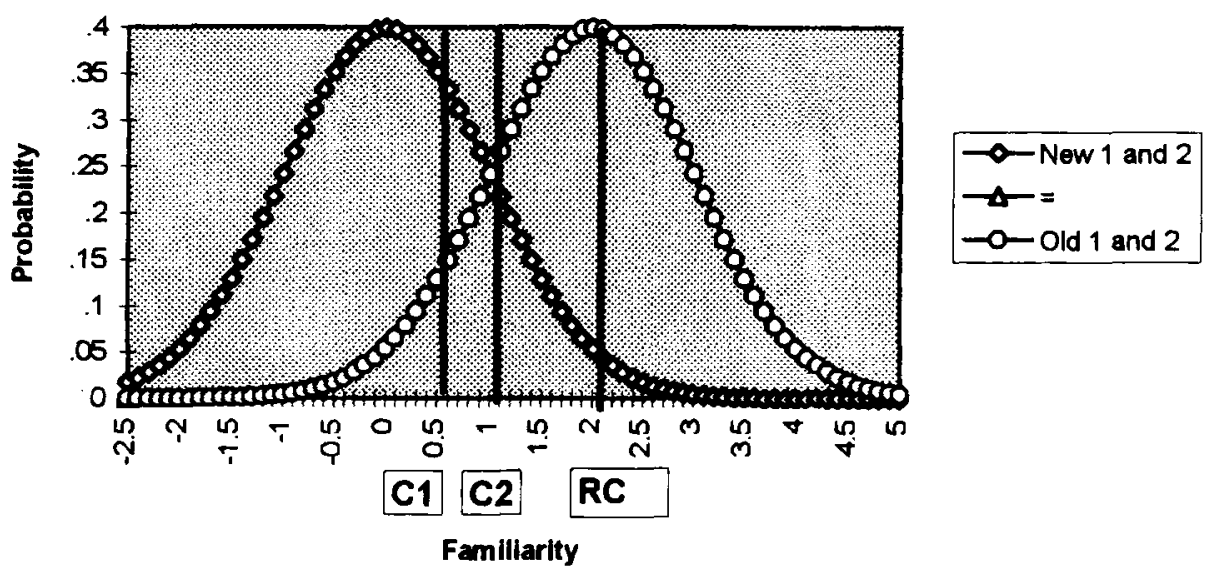

Figure 2. Modeling functional dissociations in the remember-know paradigm.

across conditions, but this cannot happen for remember responses. An example of how the relative number of know responses can change with criteria shifts is given in the top two panels of Figure 2, and one can easily envision additional examples. For example, if $\mathrm{RC}$ moves to the right in the top panel of Figure 2, there will be more know responses in old 2 than in old 1 . In contrast, as long as the ordering of the distributions representing old 1 and old 2 remains constant, there will always be more remember responses in old 2 no matter where $\mathrm{C}$ and $\mathrm{RC}$ are placed.

We examined this prediction by reviewing the prior literature. We searched the literature by using the Social 
Science Citation Index to identify papers that cited Gardiner (1988) between 1989 and 1995. From these papers, we selected those that used the remember-know paradigm to study recognition. We then examined the cases where a variable was manipulated repeatedly to determine whether the effect of that variable was always consistent on remember and know responses. (All papers used are cited in the Reference section and all effects were defined at the .05 significance level.) We identified seven cases in which a variable's effects were not completely consistent. These cases are presented in Table 1. Table 1 lists the variable, its effects on remember and know responses, and references representing the discrepant findings.

The most important point to note about Table 1 is that all seven inconsistencies occurred on know responses. The probability of this outcome occurring assuming an equal probability of inconsistencies for remember and know responses is approximately .0078 . Thus, consistent with the present model, our literature review suggests that effects of variables tend to be less reliable on know than on remember responses. In the context of this conclusion, it is important to emphasize that our review does not suggest that results from the remember-know paradigm are generally unreliable, nor that the effects of variables on know responses are necessarily unreliable. In fact, the effects of variables on remember responses are exceptionally reliable, and there are many cases in which the effects of variables on know responses are consistent (e.g., Gregg \& Gardiner, 1994; Java et al., 1995).

Although the demonstrations presented above are provocative, several cautions are in order. First, demonstrating that a model can account for various effects does not imply that the model's processes are actually producing the effects. Second, even though several anomalous findings (e.g., Knowlton \& Squire, 1995) motivated our consideration of a single-process model, a dual-process approach (Gardiner \& Java, 1993) provides an account of a large number of findings in the remember-know paradigm. Further, alternative dual-process approaches (e.g., Yonelinas \& Jacoby, 1995) may be capable of resolving some of the anomalies cited previously. Thus, despite the present demonstrations, a dual-process ap- proach may be critical to a comprehensive explanation of the remember-know paradigm.

\section{Uses of the Present Model}

The preceding comments raise an obvious question for the current model. Assuming that two memory processes operate in recognition memory (Jacoby \& Dallas, 1981; Mandler, 1980), why would one even consider a single-process model of the remember-know paradigm? In this section, we argue that even if two memory processes operate in recognition memory, the present model can be extremely useful. Specifically, formal testing of our single-process model allows us to determine which findings from the remember-know paradigm provide strong evidence for multiple memory processes and which do not. Here we describe the logic of testing the present model, providing a brief illustrative example. We then discuss some general benefits of such testing.

The present model, represented formally in Equations $1-4$, has as many parameters as data points. There are, however, straightforward ways to reduce the number of parameters. One can then (1) estimate parameters for this restricted model, (2) generate predictions based on these estimates, and (3) determine whether these predictions correspond to observed outcomes. To give one example, Hirshman and Master (1995) recently tested whether the present model could account for Gardiner, Gawlik, and Richardson-Klavehn's (1994) finding that manipulations of directed forgetting affect remember but not know responses. Hirshman and Master collected confidence ratings in recognition memory to independently estimate the variance parameters for distributions representing various experimental conditions (see Equations 3 and 4). They were able to do this because confidence ratings determine the slope of the Z-transformed ROC curve that represents a measure of the relative variances of the old and new distributions (Green \& Swets, 1966; Ratcliff, Sheu, \& Gronlund, 1992). Algebraically,

$$
Z_{\text {hit }}=\left(\sigma_{\text {new }} / \sigma_{\text {old }}\right) * Z_{\mathrm{fa}}+\left(\mu_{\text {old }}-\mu_{\text {new }}\right) / \sigma_{\text {old }},
$$

where $Z_{\mathrm{hit}}$ and $Z_{\mathrm{fa}}$ are the standardized scores corresponding to the hit rate for old items and the false alarm

Table 1

Inconsistent Effects of Variables on Know Responses

\begin{tabular}{|c|c|c|c|}
\hline $\begin{array}{l}\text { Manipulated } \\
\text { Variable }\end{array}$ & Remember & Know & Reference \\
\hline $\begin{array}{l}\text { Attention } \\
\text { (full vs. divided) }\end{array}$ & $\begin{array}{l}\text { Full }>\text { divided } \\
\text { Full }>\text { divided }\end{array}$ & $\begin{array}{l}\text { Full } \sim \text { divided } \\
\text { Full }<\text { divided }\end{array}$ & $\begin{array}{l}\text { Gardiner \& Parkin (1980) } \\
\text { Reinitz, Morrisey, \& Demb (1994) }\end{array}$ \\
\hline $\begin{array}{l}\text { Generation } \\
\quad \text { (generate vs. read) }\end{array}$ & $\begin{array}{l}\text { Generate }>\text { Read } \\
\text { Generate }>\text { read }\end{array}$ & $\begin{array}{l}\text { Generate } \sim \text { read } \\
\text { Generate }>\text { read }\end{array}$ & $\begin{array}{l}\text { Gardiner (1988) } \\
\text { Wippich (1992) }\end{array}$ \\
\hline $\begin{array}{l}\text { Levels of processing } \\
\text { (semantic vs. rhyme) }\end{array}$ & $\begin{array}{l}\text { Semantic }>\text { rhyme } \\
\text { Semantic }>\text { rhyme }\end{array}$ & $\begin{array}{l}\text { Semantic } \sim \text { rhyme } \\
\text { Semantic }<\text { rhyme }\end{array}$ & $\begin{array}{l}\text { Gardiner }(1988) \\
\text { Rajaram }(1993)\end{array}$ \\
\hline $\begin{array}{l}\text { Levels of processing } \\
\text { (self vs. semantic) }\end{array}$ & $\begin{array}{l}\text { Self }>\text { semantic } \\
\text { Self }>\text { semantic }\end{array}$ & $\begin{array}{l}\text { Self }<\text { semantic } \\
\text { Self } \sim \text { semantic }\end{array}$ & $\begin{array}{l}\text { Conway \& Dewhurst (1995, Equation 1) } \\
\text { Conway \& Dewhurst (1995, Equation 2) }\end{array}$ \\
\hline $\begin{array}{l}\text { Retention interval } \\
\text { (long vs. short) }\end{array}$ & $\begin{array}{l}\text { Short }>\text { long } \\
\text { Short }>\text { long }\end{array}$ & $\begin{array}{l}\text { Short }>\text { long } \\
\text { Short } \sim \text { long }\end{array}$ & $\begin{array}{l}\text { Knowlton \& Squire (1995, Equation 1) } \\
\text { Knowlton \& Squire (1995, Equation 3) }\end{array}$ \\
\hline $\begin{array}{l}\text { Size congruency } \\
\quad \text { (same vs. different) }\end{array}$ & $\begin{array}{l}\text { Same }>\text { different } \\
\text { Same }>\text { different }\end{array}$ & $\begin{array}{l}\text { Same }<\text { different } \\
\text { Same } \sim \text { different }\end{array}$ & $\begin{array}{l}\text { Yonelinas \& Jacoby ( } 1995, \text { Equation } 2) \\
\text { Yonelinas \& Jacoby ( } 1995, \text { Equation } 3 \text { ) }\end{array}$ \\
\hline $\begin{array}{l}\text { Materials } \\
\quad \text { (words vs. pictures) }\end{array}$ & $\begin{array}{l}\text { Words }>\text { pictures } \\
\text { Words }>\text { pictures }\end{array}$ & $\begin{array}{l}\text { Words } \sim \text { pictures } \\
\text { Words }<\text { pictures }\end{array}$ & $\begin{array}{l}\text { Dewhurst \& Conway (1994, Equation 2) } \\
\text { Dewhurst \& Conway (1994, Equation 4) }\end{array}$ \\
\hline
\end{tabular}


rate for new items, respectively. Using the variance estimates generated from the confidence ratings, Hirshman and Master found that the predictions of the restricted model were almost identical to observed outcomes.

Such model testing produces two straightforward benefits. First, and perhaps most important for proponents of a dual-process approach, it provides the opportunity to rule out a well-specified single-process model. Ruling out our single-process model places the inference that two memory processes are responsible for a particular pattern of effects on much firmer ground (i.e., the singleprocess model is used analogously to the null hypothesis in statistical inference testing). This focus on falsifying the single-process model can also operate heuristically to help researchers specify designs and procedures that will maximize the possibility of such falsification.

For example, consider the recent work of Conway and Dewhurst (1995). At study, Conway and Dewhurst asked one group of subjects to judge whether trait adjectives described themselves. They asked a second group of subjects to judge the semantic valence of these traits at study (i.e., "Does this word represent a positive or negative trait?"). They then presented a recognition memory test to each group using the remember-know paradigm. They found that even though overall recognition accuracy was approximately equal for the two groups of subjects, remember responses were much greater in the "selfjudgment" condition. Further, know responses were much greater in the "semantic judgment" condition. The present model can accommodate these findings by assuming that all processes are identical in the two groups of subjects, except that the RC criterion is lower for the self-judgment subjects. A focus on falsifying the current model suggests, however, that an experiment manipulating type of judgment (self vs. semantic) within subject could be particularly informative. Manipulating type of judgment within subject makes it very difficult for subjects to use different RC criteria for "self" and "semantic" items. Thus, replicating Conway and Dewhurst's results in a within-subject design might falsify the present model, placing inferences about dual memory processes on firmer ground.

A second benefit of testing the present model is that it provides a mechanism for generating alternative explanations of effects in the remember-know paradigm. Specifically, when the present model fits the data, it postulates a mechanism by which these effects arise (e.g., criteria shifts, mean or variance differences). This explanation can then be tested against that provided by a dualprocess conception. This may be particularly useful when results seem anomalous from the dual-process perspective.

To give one example, consider Knowlton and Squire's (1995, Experiment 1) finding that know responses are greater for normals than for amnesiacs. Whereas this finding poses a problem for dual-process approaches, it arises naturally in the present model because memory is substantially better for normal subjects than for amnesiacs. Specifically, other things being equal, the substantially higher hit rates of normal subjects will produce more know responses because of the dependency between hit rates and know responses (see the bottom panel of Figure 2 for an illustration). Thus, finding more know responses for amnesiacs may not tell us anything about multiple memory processes (see Knowlton \& Squire, 1995).

The benefits just cited show how our model can help determine which findings from the remember-know paradigm provide strong evidence for multiple memory processes. Identifying these findings, in turn, provides a firmer basis for drawing conclusions about the nature of underlying memory processes. We wish to close by emphasizing that we do not see tests between our model and dual-process conceptions as riding solely on the ability of our model to fit the data. As the discussion of Knowlton and Squire's (1995) results suggests, other classical considerations such as the simplicity of the explanation, the plausibility of parameter estimates, and the ability to generate novel predictions are all critical to identifying the most appropriate explanation. Bearing such complexities in mind, we strongly encourage the use of our singleprocess model to further theoretical understanding of the remember-know paradigm.

\section{REFERENCES}

Conway, M., \& Dewhurst, S. (1995). The self and recollective experience. Applied Cognitive Psychology, 9, 1-19.

Dewhurst, S., \& Conway, M. (1994). Pictures, images and recollective experience. Journal of Experimental Psychology: Learning. Memory, \& Cognition, 20, 1088-1098.

GARDINER, J. M. (1988). Functional aspects of recollective experience. Memory \& Cognition, 16, 309-313.

Gardiner, J. M., GaWlik, B., \& Richardson-Klavehn, A. (1994). Maintenance rehearsal affects knowing, not remembering; elaborative rehearsal affects remembering, not knowing. Psychonomic Bulletin \& Review, 1, 107-110.

GARDINER, J. M., \& JAVA, R. (1990). Recollective experience in word and nonword recognition. Memory \& Cognition, 18, 23-30.

GARDINER, J. M., \& JAVA, R. (1993). Recognition memory and awareness: An experiential approach. European Journal of Cognitive Psychology, 5, 337-346.

Gardiner, J. M., \& Parkin, A. J. (1990). Attention and recollective experience in recognition memory. Memory \& Cognition, 18, 579 . 583.

Gillund, G., \& Shiffrin, R. (1984), A retrieval model for both recognition and recall. Psychological Review, 91, 1-67.

GlanZer, M., AdAMS, J., IVERSON, J., \& KIM, K. (1993). The regularities of recognition memory. Psychological Review, 100, 546-567.

Green, D., \& SWETS, J. (1966). Signal detection theory and psychophysics. New York: Wiley.

GREGG, V., \& GARDINER, J. M. (1994). Recognition memory and awareness: A large effect of study-test modalities on "know" responses following a highly perceptual orienting task. European Journal of Cognitive Psychology, 6, 131-147.

Hirshman, E. (1995). Decision processes in recognition memory: Criterion shifts and the list-strength paradigm. Journal of Experimental Psychology: Learning, Memory, \& Cognition, 21, 302-313.

Hirshman, E., \& MASTER, S. (1995). Modeling the conscious correlates of recognition memory: Applying the theory of signal detection to the remember-know paradigm. Unpublished manuscript.

JACOBY, L., \& DALLAS, M. (1981). On the relationship between autobiographical memory and perceptual learning. Journal of Experimental Psychology: General, 110, 306-340. 
Java, R., Kaminska, Z., \& Gardiner, J. M. (1995). Recognition memory and awareness for famous and obscure musical themes. European Journal of Cognitive Psychology, 7, 41-53.

JONES, T., \& ROEDIGER, H. L., III (1995). The experiential basis of serial position effects. European Journal of Cognitive Psychology, 7, 65-86.

KNOWLTON, B., \& SQUIRE, L. (1995). Remembering and knowing: Two different expressions of declarative memory. Journal of Experimental Psychology: Learning, Memory, \& Cognition, 21, 699-710.

LECOMPTE, D. (1995). Recollective experience in the revelation effect: Separating the contributions of recollection and familiarity. Memory \& Cognition, 23, 324-334.

MANDLER, G. (1980). Recognizing: The judgment of previous occurrence. Psychological Review, 87, 252-271.

PARKIN, A. J., \& WALTER, B. (1992). Recollective experience, normal aging and frontal dysfunction. Psychology \& Aging, 7, 290-298.

RAJARAM, S. (1993). Remembering and knowing: Two means of access to the personal past. Memory \& Cognition, 21, 89-102.

RatCliff, R., Sheu, C., \& Gronlund, S. (1992). Testing global memory models using ROC curves. Psychological Review, 99, 518-535.
REINITZ, M., Morrisey, J., \& DEMB, J. (1994). Role of attention in face encoding. Journal of Experimental Psychology: Learning, Memory, \& Cognition, 20, 161-168.

Sмітн, M. (1993). Neurophysiological manifestations of recollective experience during recognition memory judgments. Journal of $\mathrm{Cog}$ nitive Neuroscience, 5, 1-13.

Tulving, E., \& SCHACTER, D. (1990). Priming and human memory systems. Science, 247, 301-306.

WIPPICH, W. (1992). Implicit and explicit memory without awareness Psychological Research, 54, 212-224.

YONELINAS, A., \& JACOBY, L. (1995). The relation between remembering and knowing as bases for recognition: Effects of size congruency. Journal of Memory \& Language, 34, 622-643.

(Manuscript received August 28, 1995; revision accepted for publication March 6, 1996.) 